\title{
Community Development And Awareness Raising In Selected Slum Areas Of Karachi Regarding Education, Health And Nutrition
}

\author{
Dua-e-Rehma \\ \& \\ Seema Manzoor \\ Centre of Excellence for Women's Studies \\ University of Karachi \\ Sadia Barrech \\ Department of Social Work \\ University of Balochistan
}

\begin{abstract}
This research paper aimed to gain further knowledge regarding the relationship between community development, education, health and nutrition. The main objective of this research is to help the slum community to explore the processes involved in tackling social issues within the community. Globally the scenario is changing as developing nations are focusing more on poverty reduction and community development, because it is now considered as the root cause of all social issues. Therefore, it is needed to evaluate the intensity of issues in order to develop effective policies and development programs to reach the SDG goals. Unstructured face-to-face interviews were conducted in selected slum areas to educate people by using educational action research for maintaining their standard of living in regard to education, health and nutrition. The main purpose of this paper was to involve respondents as research participants in order to mobilize them for future development processes within the community. Two slum areas (Ghazi Goth and Bilawal Jokhio Goth) of diverse cultures and infrastructure were selected as the population of the study. Qualitative research method was chosen to conduct in-depth study through observation and case study method. The research findings indicate that poverty is the basic issue, which needs to be addressed on priority basis, for this purpose encouraging, supporting and enabling individuals within the community can raise the awareness level by involving them through easy access to opportunities. Participants from local community can empower their own community people, because they are well aware of their culture and community issues.
\end{abstract}

Keywords: Community Development, Participatory Approaches, Poverty Reduction, Education, Health and Nutrition.

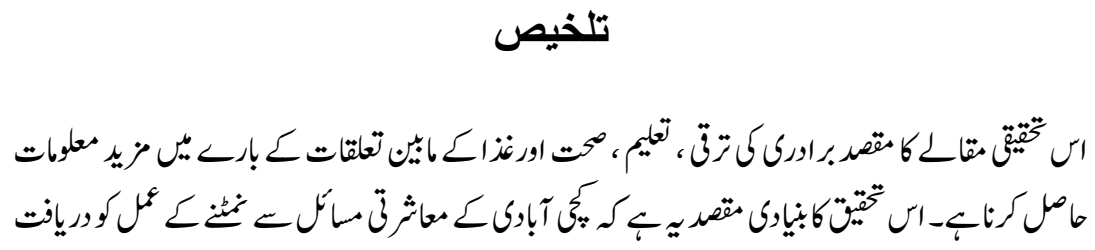




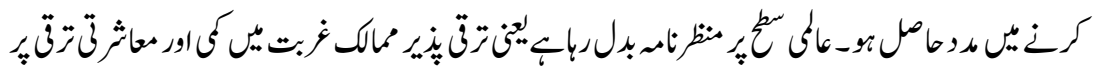

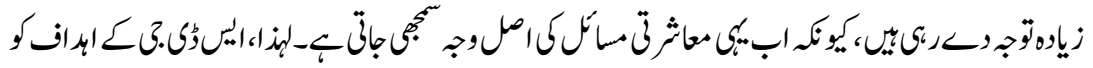

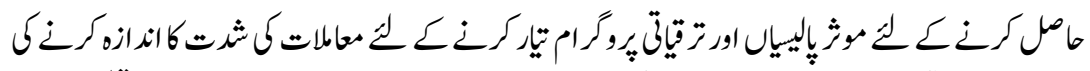

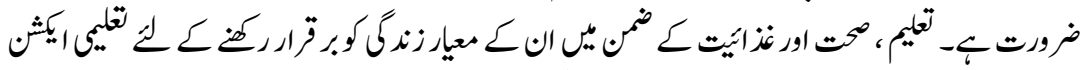

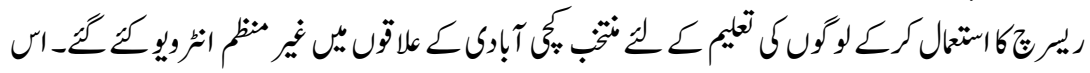

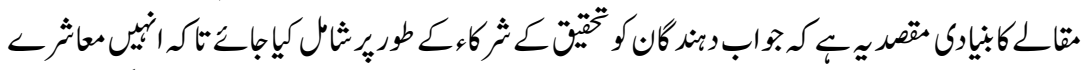

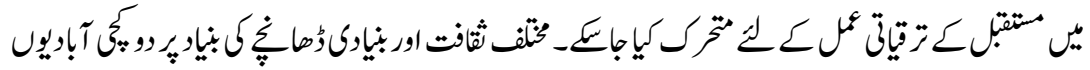

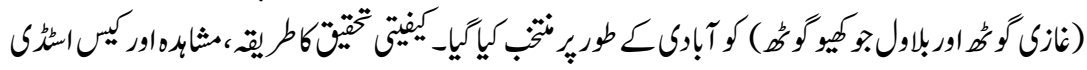

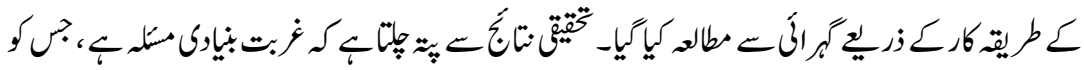

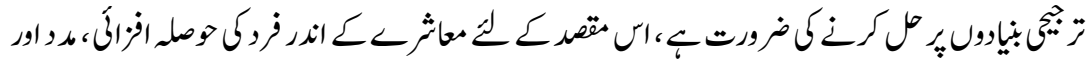

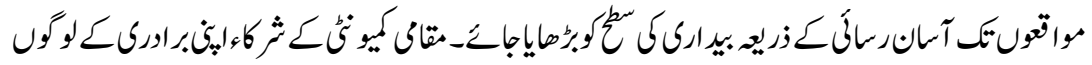

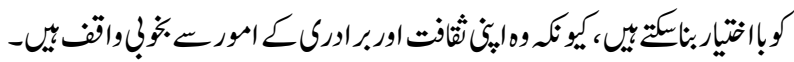

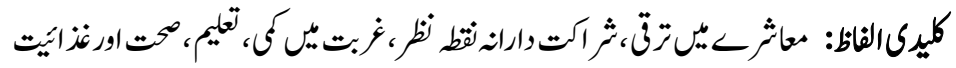

\section{Introduction}

"The world is experiencing a situation without instance: in the absence of adequate policies and programs the urbanization crisis will rise making situation more worse. Thus, the key question arises how and what policies and programs should be followed to deal the rising issue of urban crisis in Pakistan? It is important to focus on the core elements of urbanization to control the influx of rural to urban migration. This target can only be achieved by making strong policies and its proper implementation" (QADEER, 1996).

Developing nations face many socio-economic issues and one of the key problems is fast growing urbanization, which is seen as continuously increasing every decade. This issue leads to several problems like lack of basic facilities, housing, employment and access to health and education. Above all migrants face economic issues which includes expensive housing, low income therefore, they have to settle in illegal settlements. These illegal settlements give rise to slum areas due to population influx from rural to urban areas (Faheem, Mehmood \& Shah, 2016). Among all third world countries Pakistan is also plagued by the urban settlement issues and they are seemingly very acute like, housing problem, water supply, drainage, disposal waste, traffic issues and basic utilities along with social disparities and these problems are labelled as "urban crisis".

These problems are increasing with time and becoming more intense. Proper legislation is required both at provincial and governmental level to deal all the 
issues of administrative and economic institutions to improve the quality life in urban areas. It is considered that urban policies and urbanization are different regarding legislation, which is later used as reference for population attributes and economic activities for settling varying sizes of community population at national level Gnaneshwar (1995), whereas, another social scientist argues that it can be referred as "urban policies" (Richardson, 1987). The policies based on urbanization focuses on system of national settlement and the urban policies are used as tools to guide and frame the system of internal and local human settlement structure. This research aims to focus largely on issues and policies regarding community development and awareness raising in selected slum areas of Karachi regarding education, health and nutrition.

\section{Urbanization and Urbanism in Pakistan}

Basically the concept of urbanization is linked with demography of towns and cities. According to Writh, there is need to establish distinction between urbanism and urban ways of life (Wirth, 1938). It is seen that urbanism is increasing globally and urbanization is increasing at a very faster rate of population growth and this spread of urban population is known as "the urbanization of everybody" (Abu-Lughod, 1991). In Pakistan urbanism and urbanization is spreading at a very quick pace, which is definitely very alarming in terms of social structure and settlement system. This paper aims to introduce awareness among people to initiate in community development to help government in dealing development issues (O'Loughlin, Eddie \& Wegimont, Liam, 2007). Kenny thinks that community development is a process where local people supports public and private agencies in identifying issues and participates in collective efforts towards development, which can definitely create stronger bond between community members and agencies. Community development is taken as a holistic approach based on human rights, social justice, collective efforts and empowerment principles (Kenny, 2007). If awareness level is raised among community people then they can become experts of their lives as well as of their community by valuing their knowledge about their community and living spaces wisely. This way the local people gain power, i.e. community development by involvement of people become the technique of power distribution to handle the issues of inequality and social class difference present in the society.

\section{Outcomes of Community Development}

Involvement of local community people in the development process mobilizes them and they gain benefit at both individual as well as collective level. The individual families and children can benefit in regard to education, empowerment and self-dependency (Kenny, 2007). The local people become more empowered and become more competent to face upcoming challenges within their community structures, which causes them poor and negative impact on their social well-being 
(Ife, 2016). Participation of local people helps in achieving better and long lasting outcomes, Campbell, Pyett \& McCarthy (2007) for example, interconnected and organized communities with evident changes in social structure and improves health status (Wallerstein, 2006).

Urban life is more tempting, thus majority lives in urban settlements and it is estimated that by 2050 this growth will increase to two third of present statistics, especially in developing nations including Africa, Asia, India, China and Nigeria (UNDESA, 2014). Mitlin \& Satterthwaite claims that Sub-Saharan region lacks in recent statistics, therefore it is not easy to estimate the intensity of the problem (Mitlin \& Satterthwaite, 2013). Migration influx is seen more in mega cities whereas the medium sized cities are not given proper attention regarding policies and infra structure (Ghosh, 2012). Urbanization is basically linked with migration from rural to urban areas in order to seek better standard of living and income generating opportunities, but unfortunately this population growth becomes burden on urban resources (Potts, 2012a).

\section{The Expansion of Slum Settlements}

Slum areas expand due to migration from rural to urban areas as a result of lack of economic opportunities in rural settlements. Sometimes the influx of migration is so heavy that government fails in providing decent living and affordable housing to meet the needs of growing urban population. Normally slum areas settlements occur illegally therefore; these areas are neglected from benefiting government administrative boundaries. But in few cases the Lack of political will becomes the biggest hurdle in facilitating slum settlers, because government thinks that by doing so more people will be attracted, which will result in further expansion of slums. On the other hand it is not easy for the government to provide decent living to slum dwellers, because there is no statistical record of urban slums, thus it is very difficult to track the nature of these settlements and they remain unrecognized. Around 881 million people are living in slums globally and UNHabitat claims that majority of these settlements are living in developing nations (Cities Alliance, 2014).

\section{The Policy-Making Structure}

Government of Pakistan has played a pioneering role in making policies for urban areas. Since 1950s housing and some other basic provisions have been the distinct sector in five year plans. In 1972, (EUAD) the Division of Environment and Urban Affair was established under federal ministry and the local and provincial government act as agent to execute development planning. It is evident that human settlement sector does not entirely focus on the living conditions of urban areas (Mills, 1987). The current study obviously focuses on the living conditions of urban slums and on the initiatives by concerned sectors to improve their standard of living and to mobilize them by letting them participate into the development programmes to raise their level of awareness regarding education, health and nutrition. 


\section{Theoretical Background}

\section{Conceptualizing Community}

Communities are based on system theory, human ecology and field theory, which are directly related to human interaction and social infrastructure. Community is defined as people sharing same geographical area and resources to fulfill their basic needs (Matarrita-Cascante \& Brennan, 2012: p.295). However, much attention is given to develop an understanding to whether community is place based or a locality based (Giddens, 1990). In regard to this concept Bradshaw, argued that it is not necessary that a community is necessarily place based or a local place (Bradshaw, 2008). In fact it is a type of social organization, where people interact socially with each other (Goodsell, Flaherty \& Brown, 2014: p.627). Many authors have argued that community is more like a capital or asset, if focused as place based community (Flora, Flora \& Gasteyer, 2016; Green \& Hanies, 2011; Matarrita-Cascante \& Brennan, 2012). Some researchers have highlighted the fact that the local communities / slums are unprivileged groups with low or no access to material or experiential resources, which leads them to deprivation and vulnerability (Bebbington, 1999; De Hann \& Zoomers, 2005). It is also important to note that resources and capital are not the same thing, for example education for an individual can be a resource for that person to generate income but it cannot be assumed that expenses or needs can become the means to generate more income (Van Dijk, 2011: p.107). There is a comprehensive list of capital for example, humans, socio-political and cultural structure etc. each community can be distinguished on the basis of various forms of capital (Gutierrez-Montes, Emery \& Fernandez-Baca, 2009). De Hann and Zoomers emphasizes that urbanization along with its attributes has increased the mobility. With increasing urbanization, social infrastructure has also improved and the concept of planning and development has also gained importance (De Haan \& Zoomers, 2003: pp. 351,358).

\section{Conceptualizing Community Development}

Community development programmes and processes involving efforts to build and improve quality of life and well-being of community people (Wilkinson, 1991; Bridger, Brennan \& Luloff, 2011). Community development is seen as a way to organize community people to live in peace and harmony (Bhattacharyya, 2004: pp.14,25). These efforts are more like strategic efforts based on collective social efforts to organize localities harmoniously (Green, 2008:p.51). if adequate policies and investment lacks then these communities (slums) will become more deprived socially, morally, culturally and politically, thus becoming more vulnerable to suffer from poverty and other social disadvantages (Emery \& Flora, 2006). Another argument by Goodsell and other researchers highlighted that since urbanization is a global issue, therefore, all necessary aspects involving collective issues and individuals daily life must be addressed to raise their standard of living 
(Goodsell, Flaherty \& Brown, 2014: p.672,637). It is important to initiate necessary actions at geographical levels for the maintenance of communities as a priority (Bradshaw, 2008: p.15).

\section{Review of Literature}

As the world turned to modernization, the standard of living has been improved and technological development has made extravagance to basic needs. Welfare communities and governments have modified their policies to facilitated basic needs. Education is an important tool to develop, facilitate and empower the community. At this point when education is utilized viably, can change the community living standards through creation of networks locally. The primary setting for a network is driven community and the plan lies in understanding the historical backdrop of poor and its present predominance in developing nations in both urban and country settings. Hence awareness programs and education can work together for transforming the standards of living (Riegel, 2017).

Goswami (2015) pointed out that community development has multiple aspects of philanthropic work, which includes poverty alleviation, education, a job opportunity for social integration and enhancing the standard of living. Social wellbeing development is a strategy to empower every person to improve the capacity for productive tasks in the financial, social, moral, and political fields and to take part in the decisions and choices, values, social equity, and security together with social attachment and for human rights and lastly the contribution of the individuals in the holistic development. Hence it can say that every society is constructed by the different social institutions and every achievement of society is the product of successive norms establishment by these institutions (Goswami, 2015).

The world population will increase by approximately 8 billion in 2023 (United Nations, Department of Economic and Social Affairs, Population Division, 2017). Approximately $30 \%$ of the urban population living in slum areas in developing countries in 2014 (Participatory Slum Upgrading Programme Team Nairobi, 2016). People living in slums from 2.4 million in Orangi Town Karachi Pakistan to 400,000 dwellers of the South Africa region are increasing incredibly (Hutt, 2016). Slum areas are defined as an area having poor infrastructure, densely populated, insufficient water, unhygienic environment and sanitation, low standards of living and insecurity (UN-Habitat, 2017). These factors are realities for almost one billion people living in slums worldwide (Participatory Slum Upgrading Programme Team Nairobi, 2016). The process of urbanization will continue to increase and people turn over to the cities for employment and ideal life. Furthermore, many other factors are also contributed to the growth of slums such as climatic changes; war, deforestation, and drought make life harder due to these shifts. People of slums face many social problems far from economic crises including gender-based discrimination and lack of opportunities as well as health

problems like epidemics of malaria, cholera, dysentery, sexually transmitted infections, and water-borne illness. 
Slum areas experience poverty, mal-nutrition, and unavailability of necessities in terms of both access and availability. Mal-nutrition is a global social problem that has major concerns on health issues in developing nations particularly in South Asia and Sub-Saharan Africa. The problem is the cause of several factors like health, literacy and socio-economic status (El-Ghannam, 2003). Hence to deal with these problems community development approach is applied for development. Community development is the philosophy of integrating people; it is an interaction philosophy through which people of a community grow themselves. The process starts with the outsiders (philanthropists, NGOs, Government authorities) and enabling the community to change their lifestyle. According to Palmer (2007), interaction is a strategy in which community development is much more important to identify the local problems by the mouth of indigenous people and develop the ability to solve their problems by working together. If people of the community interact with the other people who have inclination to work for communities' development, will assure that community development must be for the people, by the people and about people. Interaction in community development works as a catalyst for development. Interaction is defined as the integration of community people in the process of development of their own. Imparato \& Ruster (2003) initiated the idea that the involvement of people is beneficial and having risk as well. Participation establishes positive effects on social well-being, teamwork, educational and employment opportunities, meantime participation or integration can cause any conflict, thus it is hard to meet the needs and interests. Community participation creates an ability of civic sense and awareness among the people.

The region of South Asia makes the lowest in these determinants. 35\% of the population in South Asia is residing in slums having problems of inadequate access to healthcare, education, and mal-nutrition. In developing countries, unequal distribution of facilities and resources exists in urban slums and they suffer epidemics and diseases due to poor hygiene, water and sanitation, housing infrastructure and dense population (Wong, 2018). Swaminathan H, (2012) further explained that poor infrastructure, poor hygiene, and undernourishment are the increased risk factor of poor health status. Qadeer (1996) identified the urbanization process in Pakistan as very rapidly increasing and it is transforming the social setup. About one-third of people are living in urban slums in Pakistan. The process of slum settlement in urban areas started from 1971 named katchi abadis and provision of the proprietary right of katchi abadis and facilities during Bhutto's regime. In Pakistan, urbanization is increasing with the rate of $3 \%$ annually, a rapid increasing rate in South Asia. Undoubtedly Pakistan is suffering many social problems due to mass population and Karachi is the most populace city having 13 million of population. The country and metropolitan city is experiencing the dilemma of pitiable infrastructure, transport, water and sanitation, unemployment and social security. To deal with these issues from 15 to 20 years, increasing population will be a massive test. IDPs are moving to metropolitans particularly from Khyber Pakhtunkhwa, Gilgitbaltistan and interior 
Sindh and Punjab due to military conflicts and natural disasters. The factors involve in urban migration are hope of better employment opportunities, education and to make living standards better (Kugelman, 2014).

Pakistan has ratified the 2030 Agenda for Sustainable Development in 2015. Pakistan is the first nation throughout the world, and integrated Sustainable Development Goals (SDGs) as a major element of its national development policies and frameworks and passed a resolution in national assembly for implementation in 2016. After the prospects of Millennium Development Goals (MDGs), national and provincial governments devised a taskforces to supervise the progress of objectives. Poverty Reduction Strategy programs and development programs have been established and implemented, despite of facing obstacles. Improving quality of education and easy access is a national key objective of Pakistan. The mechanism of education development emphasis in better infrastructure of schools, check and balance system with particular focus on dropout of school children. On the other hand female illiteracy is still decreased, policies are framed to increase girls enrolment in education at all levels of education which shows national interest to improve women and girls' status and to eradicate sexual inequalities (Pakistan's Implementation of the 2030 Agenda for Sustainable Development Voluntary National Review: Pakistan , 2019).

The Ministry of Planning, Development and Reform has confined PSDP 2019-20 through a broad consultative and participatory procedure. The PSDP has been lined up with monetary arrangements and procedures plot in the twelfth Five Year Plan for example financial adjustment, accomplishing adjusted territorial improvement, improving social security and destitution mitigation, lodging, increase of water assets, vitality and nourishment security, creating serious information economy and modernization of transport foundation and more noteworthy local network (SDG, June, 2019).

\section{Role of Women in Community Development}

Women are the essential and primary care takers of children and older family members throughout the world. Global studies exhibit that when the economy and political association of a general public change, women start to lead and helping the families during challenges and difficulties. They are probably going to be the prime initiator, and perform a significant role to improve living standard of their families. Women of the rural areas perform key jobs in supporting their family units and networks, in accomplishing food and sustenance security, generating income and improving local employments and prosperity (Global Volunteers, 2019).

Furthermore, a unique exertion ought to be made to incorporate the most powerless and frequently ignored individuals from the network, generally involved women, children of all ages particularly orphans, widows, older persons etc. (Hatfield, 2016). These individuals may not go to the gathering, or the social structure. In 
such situation, it might be useful to have advocates from the local medical facility and educational organizations who can talk on their behalf. Community development which provides women awareness and education through involving them in the process is the starting point of development (Michael, Kenny).

A research analysis about Nigerian women involved in community development through examining the impact of Annual August meeting in South East Nigeria. The results mention that women involved in community development have the potential and capabilities to bring a social change and harmony. They can be a part in contributing a sustainable development which is a chain of the Millennium Development Goals. It argues about the role of women in the journey for supporting sustainable development over community development. Furthermore, women have a great contribution in peace making, good governance and achieving Sustainable Development Goals (Ohaegbuchi, 2014).

The interest and participation of women is a way to accomplish the objectives of development, through gender awareness and economic policies. It will add in achieving economic development, yet it will likewise help to recognize the social objectives of the society. Indeed, a view about increasing contribution of women's decision making will be helpful in achieving the Sustainable Goals at all levels (Unongu, 2016).

\section{Objectives}

1. To explore the processes involved in tackling social issues within the community

2. To find out the issues slum community face due to poverty.

3. To analyze the awareness level of slum communities regarding their health and nutrition.

4. To explore do the slum communities value education and its importance.

5. To analyze how community individuals can be encouraged and supported within community for their betterment.

6. 10. To find out how policies can be effectively implemented to raise the standard of living.

\section{Methodology}

Keeping in mind the research topic the qualitative approach has been used as research methodology. The main purpose of this paper was to involve respondents as research participants in order to mobilize them for future development processes within the community. Group discussions were also initiated during data collection process in order to get the first hand knowledge about their problems and their mindset. Two slum areas (Ghazi Goth and Bilawal Jokhio Goth) of diverse cultures and infrastructure were selected as the population of the study. Qualitative research method was chosen so that in-depth study can be conducted through observation and case study method. In this regard purposive 
technique of non-probability sampling was used for bridging the gap of information between slum communities and development authorities. Unstructured face-to-face interviews were conducted in selected slum areas to identify the diversity of their cultures based on religion, ethnicity and infrastructure along with a motive to educate people about maintaining their standard of living through awareness raising in regard to education, health and nutrition. In this study educational action research is used to explore the human experiences, problem solving, social engagement and communication with the environment along with demonstrating community development practices.

\section{Data Analysis}

Data analysis was carried out in fragments meticulously. Initially questionnaire was administered in Urdu language to obtain clear opinion and response of the participants, and then responses were recorded. This whole process was based on group discussions as well. The interviews were then translated into English to incorporate in the final report. Later the data was presented through case studies based on selected communities and provided the in-depth knowledge about the research subject.

\section{Educational Action Research}

It is a way to enquire and carry out things in a manner to establish understanding along with evaluation to change existing social and educational practices. Educational action research is generally opted by the researchers to investigate human experiences, social engagements so that community development practices can be exercised within the communities (Costello, 2007).

\section{Observation}

Observation is a way to collect data systematically to record people's opinion and to examine the observable facts noted during observation process in the given natural conditions, which are caused by the unintentional circumstances and events. Observation is a prolonged session of data collection, which is carried out till the researcher obtains the required facts to conclude the findings. It is used to record behaviour of people without interventions in their routine life. Basically it records things and events in the order of their occurrence without letting people know that their behaviour is recorded by the researcher being the part of their setup (McBurney \& White, 2009).

\section{Case Studies}

Case study is a qualitative method of data collection. The research problem is clearly highlighted and understood through case studies, as it is a way to establish an in-depth analysis. Case study not only provides the current and updated knowledge but it also authenticates the previous knowledge, which is gained from 
the previously conducted researches. Case study is a diverse medium of qualitative research, because it provides detailed analysis about an individual, a group of people, community, institutions, region, city or even country or continent, which is based on human experiences, societal facts and cultural practices (Yin, 2012).

Case study method is used by the researcher purposively so that every possible detail can be documented regarding the community development and awareness raising based on education, health and nutrition. This research aims to establish understanding about the problems of slum areas and to let these local people contribute in problem solving process on their own as well. The involvement of the localities for the purpose of developing their own community can change the attitude of these people to be able to solve the problems on their own so that they can become independent, rather than looking forward for external help.

\section{Case Studies}

\section{Karachi: Case Studies of Ghazi Goth Case Study 1: Aashu Bibi}

Aashu bibi is a 45 year old married woman, living in Ghazi Goth opposite to University of Karachi. They are living here for 15 years and their family came to Karachi from Raheem Yaar Khan in search of job, so that they can improve their standards of life. Her husband Muneer Ahmed is a drug addict and doing nothing. Aashu bibi and her five sons work to manage bread and butter. Aashu and her husband are illiterate and also unable to provide education to their children due to financial issues. Three of the sons are rickshaw driver while two sons are daily wagers.

They live in this katchi basti for many years and facing many problems. Ghazi goth is ill-legal and does not have any proper infrastructure. This area lacks in basic necessities of living like electricity, gas and water. Their house structure is semi structures (katcha pakka) and even do not have a facility of proper washroom and sewerage system. According to her, they face problem from Police men, who demands money from them and exploits them by displacing them from their area due to illegal settlement. People of this basti are also not interested in developing their community and as a result they suffer from epidemics such as jaundice, gastric problems and pediatric diseases. She expressed her vision that there should have proper school set up so that basti children can get education and have a bright future.

\section{Case Study 2: Shahnaz Bibi}

Shahnaz Bibi is a 25 years old widow woman having a 2 years old daughter. She is been living in Ghazi Goth for four years. Her daughter is the only family she has and her husband died one year ago due to heart attack. She feels safe in this basti as people of the basti are very caring and co-operative. She works in houses 
as domestic maid to fulfill their needs. She keeps her daughter with her during work. She has no facilities in her house and the construction is semi-constructed. She only earns 3000 rupees which is insufficient to fulfill their needs. She is Saraiki and basically belongs to a village Raheem Yar Khan. She has no other family member and relative in Karachi. She is suffering in kidney diseases and while her daughter is also a heart patient.

\section{Case Study 3: Samreen Akhter Ahmed}

Samreen Akhter Ahmed is a 19 year old young woman. She is married and has two sons. She lives in joint family system and her father in law is the head of the family. The whole family is uneducated. Both husband and wife work to meet the needs. Her husband works as a painter and she works as domestic maid, her working hours are from 7:30 am to 9:30 pm and earn almost 6000. Both husband and wife are trying to fulfill their needs by doing work together. They somehow manage to send their one son to government school of the area. They want to educate their sons and working hard to educate both sons, therefore she is also working to help her husband. She said me and my husband now understand the importance of education, so we shall educate our children. Her in laws are living here for 15 years and she came to Karachi after her marriage. The house is a hut consists of a single room, courtyard, a separate kitchen and a bathroom which is a temporary arrangement. They do not have access to basic utilities, because the basti is illegal and they constantly have fear of being displaced. They face many problems during raining season. Samreen said child marriage culture exists in their community, which is not a good social practice.

\section{Karachi: Case Studies of Bilawal Jokhio Goth Case Study 4: Mairaj Bibi}

Mairaj bibi is a 50 years old woman, living in a joint family system in Bilawal Jokhio Goth, her husband Haji Mohammad is the head of the family. Mairaj bibi and her husband both are illiterate, she cannot even talk in Urdu properly but do understand Urdu very well. Their mother tongue is Pushto. They live in their own house having one main hall and three bedrooms. They are basically from Swabi and settled here 30 years ago. Her husband is 70 years old and is now enjoying his retired life. She has three sons and two daughters, all of them are married. Daughters are living in Swabi with their in laws, and her sons are living with

them. Her eldest son is doing the job of gardener in army units (MES) and the second son is also doing the same work in private houses, and the youngest son is working as private driver. Mairaj bibi has five brothers and four sisters, they all live in Swabi and she often visits them. Since Haji Mohammad is doing no work because of his age, so their sons are supporting them, but they are doing low paid jobs, it becomes difficult sometimes to cope up with such situation due to inflation. Mairaj bibi has cervical problem and she is not getting proper medication and treatment due to poverty. Mairaj bibi and her family is facing 
financial issues. She cooks food for herself and her husband separately though living in joint family. They all manage their own expenses.

\section{Case study 5: Meena Khan}

Meena Khan is 40 years old woman, and her husband Ibrahim Khan is a gardener and works in private houses, he earns 15,000 rupees. She lives in joint family system with her in laws. Her father in law is the head of the family. They have total ten family members, three males, three females and four children. Her husband do not permit her to do any kind of job, but if it is needed and that too temporarily, for example after child birth or in case of increase in expenses. They speak Urdu and Pushto both fluently and Nowshera is their native town. They settled here in Krachi (Bilawal Jokhio Goth) 20 years ago. Meena and her husband both are uneducated. She has four children two sons and two daughters of ages 9 years, 8 years, 6 years and 5 years respectively. They cannot afford to educate all their children and only one son (who is 8 years old) goes to school. Her second daughter Fatima is very intelligent and they want her to get education but cannot manage the expenses. They are unable to meet the basic needs of life in limited amount of their income. Their utility bills, water tax and school fee of a son is almost 5,000 and rest of the money is used for food and clothing, but it is not sufficient sometimes they take loan from relatives and it becomes hard to return the loan due to low income and financial issues. Their condition was very devastating regarding health and hygiene. Their community has now gas and electricity facility but still lack in proper sevrage system. Meena has several health issues due to mal-nutrition and suffers from lack of health facilities. They are living in sub-standard living conditions due to their limited means of resources and trying hard to manage their daily needs.

\section{Case Study 6: Khalida Gul}

Khalida Gul is 20 years old and her husband Gul khan is a driver and earns around 18,000 rupees, and is the head of the family as they are living in nuclear family. They got married eight years ago and are first cousins in relation. They are from Swabi and settled down here after marriage and now they have two children. Khalida has six brothers and four sisters living in Swabi. Six years ago she lost a baby after delivery, because they could not afford to go to hospital and she had an emergency during night and did not have much time to reach hospital. The delivery was supposed to occur by caesarian, therefore the baby died due to complications during birth but Khalida got a new life luckily. She was in shock at that time and suffered from post partum trauma on losing her baby. There are schools and private clinics to facilitate local people. Khalida is very responsible and wise and within his husband's salary she somehow manages the expenses and tries to run her home smoothly. 


\section{Results and Discussion}

Slums are residential areas having sub-standard housing with habitants living in close and crowded settlements; therefore, people suffer from unhealthy environment, unsafe and socially undesirable setup. Any such community living can be categorized as slum, but usually this term is used in larger context i.e. more commonly as urban slums. Slums have always existed in large cities but, it became more extensive with the growth of these cities. An urban slum is considered as a growing global issue, which has been increasing constantly. The standard of living is also declining at a constant rate. Despite the facts that people come to urban areas for income generation and to have a quality of life. Slum dwellers live in sub-standard urban areas commonly known as Urban Slums and Squatter settlements. Researches on Community Development have found that communities face many social problems. The current study shows that lack of basic resources, water and sanitation, malnutrition, illiteracy, poor infrastructure and cultural hindrances are the factors that prevent slum dwellers to involve in socio-economic development. Community based organizations commence the practice of participation of slum dwellers for self improvement and improved living standards. The purpose of outcast interventions in community should be sustainable for upcoming generations. Education is an ultimate practical need for human development; furthermore lack of education is the main component of causing poverty. Same results can be seen in the following, as people of slum communities know the vitality of education, as education attainment is the main source for achieving quality life. Hence by involving community members and educating them to deal with their issues is a better way to have positive results. Education can be used as an effective tool for improving community's status and understanding the causes of poverty and sub-standard living. Unprivileged people need to have access to knowledge about different Government plans and to be their collaborating partner through the private sector. Equitable distribution of assets and necessary training regarding community work and regulatory process must be considered as a must part of community development. For the eradication of malnutrition and poverty, health services and nutritional programmes are needed to initiate social mechanisms for poor households. There is also a need to maintain an infrastructure, waste management system, providing clean drinking water and appropriate sanitary waste disposal are the significant interventions linked with urban development programme.

According to the research findings it has been observed that wage is not in accordance to the social needs of people i.e. housing, health expenses, food and education etc. which definitely adds into family's poverty. Slum areas already constitute of complex issues for example, slum locality is usually engaged in low paid jobs, and thus they cannot afford costly living. But somehow they manage the housing structure and housing condition in slum localities. Government should focus on slum areas issues within urban space to deal internal composition and relevance of policy actions and designs. As slum areas are the population segment of urban population thus urban slums should be given importance to have control over issues like governance, crime, corruption and regulations and all these steps 
can become effective by government intervention and political will. Slum area people are forced to live in poor standard living, because they cannot afford decent living. Such population structures leads to more poverty and adds burden on national economy. Slum localities are not under the government control, because these are illegal settlement usually, which increases social inequality and imbalance due to heavy migration from rural to urban settings. It is an established fact that poor people live in slums, thus they are the cause of increase in slum population. According to sociological facts cities with successful infrastructure attracts poor for income generation whereas, the failing cities are the cause of creating slums with intense poverty issues. Along with all other issues they are prone to health and nutritional issues, since they do not have access to health care services. Thus, they suffer from lack of protein based diet, anemia, deficiency of vitamin A, iron and calcium. The health and nutritional status of slum dwellers is not satisfactory, especially the biggest sufferers are women and children.

In developing nations these issues have been controlled to certain extent by increase in per capita income and strict health and housing regulations. Unequal distribution of resources, especially economic resource, increasing class difference, injustice and poverty are basically taken as main cause of rise in urban slums. People usually migrate from rural to urban areas for the purpose of employment and income generation, but still they face problems and feel themselves as misfit in urban system due to lack of planning, lack of formal housing and poverty. Moving to big and industrialized cities does not solve their economic issues; they remain unprivileged and suffer from poor health, malnutrition, and no access to education and mainstream participation. Due to the negligence of government and private sector they suffer from severe mal-nutrition and health issues, their lack of awareness adds more into their troubles. In order to improve their living conditions, health and nutrition problems, sub-standard living conditions, poverty, low access to education and local and mainstream development serious and direct interventions are required.

Development can be done only on the basis of appropriate measures taken in the right direction and for this purpose the authorities should understand the core issues of slum areas. Basic issues of any slum locality are 1) poor housing, 2) lack of public services and 3) illegal settlement of slum dwellers. Security and sanitation are also important factors to be addressed along with the above mentioned factors. Delay in urban development strategies, lack of public-private partnership collaboration programmes, making adequate policies and improving per capita income are the contributing factors in making the issues more intense not only in slum settlements but also in urban settlements. Unequal distribution of justice, economic and political rights and civil rights is giving rise to crime, begging and child labour as well. Almost all developing nations face similar problems of slums and they are constantly accelerating and thus becoming uncontrollable. Pakistan is also undergoing urban transformation due to heavy migration from rural to urban areas. Lack of basic infrastructure and lack of political will is enhancing the issues like issue of affordable and decent housing, 
environmental issues, water and sanitation issues, health and nutrition issues and above all the lack of access to education and employment. These issues can raise severity in problems of slum settlers, which in turn will become more challenging for the authorities to tackle if proper measures are not taken.

\section{Conclusions}

Slum areas are overcrowded and substandard living areas, where people are deprived of basic necessities and living in unhealthy, unsafe and undesirable living settlements. Urbanization and migration from rural to urban areas has increased due to urban industrialization. It has become a global issue, but the problem is more intense in the developing nations and is termed as squatter settlements. Due to heavy migration from rural areas to cities becomes burden on regional and national resources. This growth affects both humans and the environment, because the people of slum areas live under many threats like physical, housing, health and other social necessities. Uncontrollable expansion of slums can become threat to sustainable development as well at all urban development levels.

Karachi being a cosmopolitan city feeds millions and generates revenue for the whole country. Besides these benefits it suffers from law and order situation, street crime, poverty, violence and poor infrastructure. Urbanization on the one hand provides man power and human resource and boosts national economic growth, but on the other hand it is intensifying urban issues. With increasing urban population housing, transportation, education, health facilities, water and energy crisis is becoming worse and more challenging with each passing day. Federal and provincial governments should focus on how to control heavy human influx to urban areas and to provide basic facilities to every citizen in rural and urban settlements, otherwise increasing poverty and burden on urban resources will reverse the national economic growth. Big cities of Pakistan are expanding but beyond that urbanism is expanding at a faster pace than urbanization, therefore social infrastructure and population structure is also transforming. Almost one third of the Pakistan's Population is composed of urban settlers. Urbanization and urbanism have reasons which cannot be denied and due to lack of appropriate policies it does not seems easy to control the issues of big cities.

In Pakistan squatter settlements trend started in the year 1971, these Katchi Abadis became the political constituencies of political parties and thus it was not easy to send them back to their native land. These illegal communities have become a severe threat in many ways. Since they fail to achieve decent living and employment opportunities due to their low standard living and illiteracy, therefore they get involved in crime and other illegal acts. The government should intervene to organize these communities in order to bring these people into mainstream rather than letting them involve in anti-social and criminal activities. Public and private sector should collaborate to facilitate these poor people, especially women and children to survive and to have a decent living as their basic right. There seems to be lack of coordination between government and private sector, which leads to 
exhaustion of resources. It has been noted that poor infrastructure, poor policies and lack of improvement programmes in slum areas making living conditions more worse. Slum areas are part of urban population, but they are not linked with city infrastructure. Slum people do not get a chance to participate in development process directly; either they participate through counselors or local leaders. They are deprived of getting education, healthcare services and proper nutrition. Government should exercise policies to improve their living standard and should incorporate them in development processes to make them aware of the process and to let them help themselves to grab their bounties. Public and private sector should initiate and collaborate to start cost effective solutions for health, nutrition and awareness raising programmes along with development programmes. These programmes cannot give fruitful results without active participation of local community people. Poor health and nutritional status is the most concerned aspect of slums, particularly among women and children. The situation needs to be addressed on urgency basis and targeted interventions are required to provide education, healthcare facilities and nutritional care to the slum dwellers.

\section{Limitations and Delimitations}

The basic aim of this study is to find out perception, attitude and involvement of localities in their own social development. It was a very challenging task to involve them slum area people in development projects and provoking them to get motivated to help themselves to change their life style and living pattern. The main hurdle in development is the cultural constraints and illegal settlements, which hinders in overall development of their communities. Their values, norms and belief systems are very strong and it is very difficult to convince them to change their path and to get involved in the mainstream process of development to become productive for their communities and as well as for the economic and national growth. Researcher was very curious and careful while asking questions so that the respondents might not feel offensive and the questions should not be provocative in nature. Their cultural approach becomes a personal matter, when a person faces different opinion other than his/her values. Thus interviewing people is not an easy task. But first taking the authorities in confidence it became a bit easy to interview them. The respondents gave interview after getting assurance that their personal details will not be used anywhere neither directly nor indirectly.

\section{Recommendations}

1. Local people should get involved in the community Development to raise their standard of living.

2. Local community development departments should intervene in collaboration with local people in order to educate them.

3. Local committees should be formed under the supervision of government and private sector to solve the problems at community level. 
4. Pluralistic approach and self-awareness regarding community development should be adopted.

5. Development initiatives are a need of the time and attention must be drawn to the demographic and socio-economic attributes.

6. For the welfare and well-being of community people development network between broader structural infrastructure and latest communal trends should be established for letting people to have easy access to resources and opportunities.

\section{References}

Abu-Lughod, J. (1991) Urban Sociology. New York, Harper Collins.

Bebbington, A. (1999). Capitals and Capabilities: A Framework for Analyzing Peasant Viability, Rural Livelihoods and Poverty, World Development, vol.27, pp.2021-2024.

Bhattacharyya, J. (2004). Theorizing Community Development, Community Development, vol. 34, pp.5-34.

Bradshaw, T. (2008). The Post-Place Community: Contributions to the Debate about the Definition of Community, Community Development, vol.39, pp.5-16.

Bridger, J. C., Brennan, M. A. \& Luloff, A. E. (2011). The Interactional Approach to Community, In Robinson, J. W., Green, G. P. (Eds.), Introduction to Community Development: Theory, Practice and Service-Learning, Los Angeles, CA: Sage, pp. 85-100.

Campbell, D., Pyett, P. \& McCarthy, L. (2007). Community Development Interventions to Improve Aboriginal Health: Building an Evidence Base, Health Sociology Review, vol.16, pp.304-314.

Cities Alliance (2014). About Slum Upgrading, Available at www.citiesalliance.org/sites/citiesalliance.org/files/CA_Images/SUFact sheet_English_0.pdf).

Costello, P.J.M. (2007). Action Research, London, Continnum, p.3.

De Haan, L. \& Zoomers, A. (2003). Development Geography at the Crossroads of Livelihood and Globalization, Journal of Economic and Social Geography, vol.94, pp.350-362.

De Haan, L. \& Zoomers, A. (2005). Exploring the Frontier of Livelihoods Research, Development and Change, vol.36, pp.27-47. 
El-Ghannam, A. R. (2003). The Global Problems of Child Malnutrition and Mortality in Different World Regions, J Health Soc Policy, vol.16, pp.1-26.

Emery, M. \& Flora, C. (2006). Spiraling Up: Mapping Community Transformation with the Community Capitals Framework, Community Development, vol.37, pp.19-35.

Faheem, M., Mehmood, B. \& Shah, M.N. (2016). Exploration of Socio-Economic Problems of the Inhabitants of Slum Areas and their Impact on Vicinity Residents: A Case Study of Arifwala Pakistan, Sci. Int.(Lahore), vol.28:5, pp.7-13, ISSN: 1013-5316; CODEN: SINTE 87 SeptemberOctober

Flora, C. B., Flora, J. L. \& Gasteyer, S. P. (2016). Rural Communities: Legacy + Change (5th ed.), Boulder, CO, Westview Press.

Ghosh, J. (2012). The Challenges of Urbanisation May be Even Greater in Smaller Towns, Guardian Poverty Matters Blog, Available at www.theguardian.com/global-development/poverty-matters/2012/oct/ 02/challenges-urbanisation-greater-small-towns).

Giddens, A. (1990). The Consequences of Modernity. Cambridge, England, Cambridge University Press.

Global Volunteers (2019). Development Impact, Reaching Children's Potential The Global Role Of Women - Caretakers, Conscience, Farmers, Educators And Entrepreneurs, Global Volunteers.

Gnaneshwar, V. (1995). Urban Policies in India: Paradoxes and Predicaments, Habitat International, vol.19:3, pp. 293-316.

Goodsell, T. L., Flaherty, J. \& Brown, R. B. (2014). Community as Moral Proximity: Theorizing Community in a Global Economy. In Bailey, C., Jensen, L., Ransom, E. (Eds.), Rural America in a Globalizing World: Problems and Prospects for the 2010s, Morgantown, WV, West Virginia University Press, pp.626-641.

Goswami, S. (2015). Slums and Social Development: A Search for Alternative Paradigms, Russian Journal of Sociology, Vol. 1(1), pp. 12-18. Access from https://www.researchgate.net/profile/Sribas_Goswami2/ publication/275036906_Slums_and_Social_Development_A_Search_fo r_Alternative_Paradigms/links/5926) and-Social-Development-A-Search-for-Alternative-Paradigms.pdf

Green, G. P. \& Haines, A. (2011). Asset Building and Community Development (3rd ed.), Thousand Oaks, CA, Sage. 
Green, J. J. (2008). Community Development as Social Movement: A Contribution to Models of Practice, Community Development, vol.39, pp.50-62.

Gutierrez-Montes, I., Emery, M. \& Fernandez-Baca, E. (2009). The Sustainable Livelihoods Approach and the Community Capitals Framework: The Importance of Systems-Level Approaches to Community Change Efforts, Community Development, vol.40, pp.106-113.

Hatfield, S. (2016, February 24-25). Level 2 Training: Introduction to International Humanitarian Response. Seminar Presented for Liberty University Send Now, Lynchburg, VA.

Hutt, R. (2016). These are the World's Five Biggest Slums, World Economic Forum, Retrieved from https:/www.weforum.org/agenda/2016/10/ these-are-the-worldsfive-biggest-slums/

Ife, J. (2016). Community Development in an Uncertain World: Vision, Analysis and Practice (2nd ed.), Port Melbourne, Cambridge University Press.

Imparato, I. \& Ruster, J. (2003). Slum Upgrading and Participation: Lessons from Latin America, Washington, D.C.:, The World Bank, Accessed from http://documents.worldbank.org/curated/en/277391468765324276 /pdf/multi0page.pdf

Kenny, S. (2007). Developing Communities for the Future (3rd ed.). South Melbourne, Thompson.

Kugelman, Michael (2014). Pakistan's Runaway Urbanization: What Can Be Done? Washington, DC, Woodrow Wilson International Center for Scholars. Accessed from www.wilsoncenter.org/program/asia-program

Matarrita-Cascante, D. \& Brennan, M. A. (2012). Conceptualizing Community Development in the Twenty-First Century, Community Development, vol.43, pp.293-305.

McBurney, Donald H. \& White, Theresa L. (2009). Research Methods, Belmont, CA, Wadsworth Cengage Learning, p. 222.

Michael, Kenny (2003). Community Education and Development, Ireland, NUI Maynooth Community, p.13.

Mills, E. S. (1987). Non-Urban Policies as Urban Policies, Urban Studies, vol. 24, pp. 561-569.

Mitlin, D. and Satterthwaite, D. (2013). Urban Poverty in the Global South, London, Routledge. 
O’Loughlin, Eddie \& Wegimont, Liam (2007). Global Education, Public Awareness- Raising and Campaigning on Development Issues: An Overview of Evaluation Practice and Policy, Bonn, Germany, Hosted by the German Ministry for Economic Co-operation and Development $(\mathrm{BMZ})$ and the OECD Development Centre, p.3.

Ohaegbuchi, Moses Ugochukwu ( April 2014). Women in Community Development: Interrogating The Role of Women August Meeting in South East, Net Journal of Social Sciences, vol.2:2, pp.44-52.

Palmer, Jeff (2017). Ethics \& Religious Liberty Commission. Accessed from https://erlc.com/resource-library/author-index/jeff-Palmer

Planning Commission Ministry Of Planning, Development And Reform (June, 2019). Public Sector Development Programme 2019-20, Pakistan, Government of Pakistan Accessed from https://www.pc.gov.pk/uploads/archives/PSDP_2019-20_Final.pdf

Potts, D. (2012a). Whatever Happened to Africa's Rapid Urbanisation?, Counterpoints, Available at (www.africaresearchinstitute. org/files/counterpoints/ docs/ Whatever-happenedto-Africasrapidurbanisation-6PZXYPRMW7.pdf).

Qadeer, M.A. (1996). An Assessment of Pakistan's Urban Policies, 1947-1997, The Pakistan Development Review, vol. 35(4) Part II (Winter), pp. $443-465$.

Richardson, H. W. (1987). Whither National Urban Policy in Developing Countries, Urban Studies, vol.24, pp.227-244.

Riegel, Leanne (2017). The Role of Education in Self-Sustaining Community Development Liberty University. (Unpublished Thesis), Accessed from https://digitalcommons.liberty.edu/honors/706

SDG. (2019). Pakistan's Implementation of the 2030 Agenda for Sustainable Development Voluntary National Review: Pakistan Section Ministry of Planning, Development and Reforms Government of Pakistan Accessed from https://sustainabledevelopment.un.org/content/documents/ 233812019_06_15_VNR_2019_Pakistan_latest_version.pdf

Swaminathan, H. \& Mukherji, A. (2012). Slums and Malnourishment: Evidence from Women in India, Am J Public Health, vol.102, pp.1329-1335.

UNDESA. (2014). World Urbanization Prospects: The 2014 Revision, Highlights, New York, United Nations Department of Economics and Social Affairs, Available at (http://esa.un.org/ unpd/wup/highlights/wup2014highlights.pdf). 
UN-Habitat. (2017). Housing and slum upgrading. Accessed from https://unhabitat.org/urban-themes/housing-slum-upgrading/

United Nations, Department of Economic and Social Affairs, Population Division. (2017). World population prospects: The 2017 revision, key findings and advance tables. Accessed from https://esa.un.org/unpd/wpp/ Publications/Files/WPP2017_KeyFindings.pdf

Unongu, Moses Atogo (2016). The Role of Women in Community Development, Nigeria, Available at https:/www.academia.edu/34129032/THE_ROLE _OF_WOMEN_IN_COMMUNITY_DEVELOPMENT

Van Dijk, T. (2011). Livelihoods, Capitals and Livelihood Trajectories: A More Sociological Conceptualization, Progress in Development Studies, vol.11, pp.101-117.

Wallerstein, N. (2006). What is the Evidence on Effectiveness of Empowerment to Improve Health?, Copenhagen, World Health Organization.

Wamukoya Damazo, Marylene (2020). The Nairobi Urban Health and Demographic Surveillance of slum dwellers, 2002-2019: Value, processes, and challenges, Global Epidemiolog, vol. 2.

Wilkinson, K. P. (1991). The community in rural America, New York, NY, Greenwood Press.

Wirth, L. (1938) Urbanism as a Way of Life. American Journal of Sociology, vol.44, pp.1-24.

Wong, E. \& Shankar, P. (2018). A Feasibility and Pilot Study in Nutrition Intervention for Child Health, Bangalore, India, Indian J Nutri, vol.5, p.192.

Yin, Robert K. (2012). Applications of Case Study Research (ed. 3), Los Angeles, USA, Sage Publications, pp.3-6, 9-10.

Dua-e-Rehma is Lecturer in the Centre of Excellence for Women's Studies, University of Karachi, Karachi, Pakistan.

Dr. Seema Manzoor is Assistant Professor in the Centre of Excellence for Women's Studies, University of Karachi, Karachi, Pakistan.

Dr. Sadia Barrech is an Assistant Professor in the Department of Social Work, University of Balochistan. 